Article

\title{
Investigation of the Structural, Mechanical and Tribological Properties of Plasma Electrolytic Hardened Chromium-Nickel Steel
}

\author{
Bauyrzhan Rakhadilov ${ }^{1,2}$, Ainur Seitkhanova ${ }^{3}$, Zarina Satbayeva ${ }^{1,4, * \mathbb{C}}$, Gulnara Yerbolatova ${ }^{5}$, Yulianna Icheva ${ }^{6}$ \\ and Zhuldyz Sagdoldina ${ }^{1}$ \\ 1 Research Center Surface Engineering and Tribology, Sarsen Amanzholov East-Kazakhstan University, \\ Ust-Kamenogorsk 070000, Kazakhstan; rakhadilovb@mail.ru (B.R.); sagdoldina@mail.ru (Z.S.) \\ PlasmaScience Ltd., Ust-Kamenogorsk 070000, Kazakhstan \\ 3 Department of Physics, Pavlodar Pedagogical University, Pavlodar 140000, Kazakhstan; ainur1179@mail.ru \\ 4 Institute of Composite Materials, Ust-Kamenogorsk 070000, Kazakhstan \\ 5 Department of Physics, D. Serikbayev East-Kazakhstan Technical University, \\ Ust-Kamenogorsk 070000, Kazakhstan; e.gulnara_77@mail.ru \\ 6 Department of Metallurgy and Natural Science Disciplines, Academician K. Satpayev Ekibastuz Engineering \\ and Technical Institute, Ekibastuz 141200, Kazakhstan; isheva1967@mail.ru \\ * Correspondence: satbaeva.z@mail.ru; Tel.: +7-(777)-300-09-39
}

Citation: Rakhadilov, B.;

Seitkhanova, A.; Satbayeva, Z.;

Yerbolatova, G.; Icheva, Y.;

Sagdoldina, $Z$. Investigation of the Structural, Mechanical and Tribological Properties of Plasma Electrolytic Hardened

Chromium-Nickel Steel. Lubricants 2021, 9, 108. https://doi.org/

10.3390/lubricants9110108

Received: 23 July 2021

Accepted: 30 October 2021

Published: 4 November 2021

Publisher's Note: MDPI stays neutral with regard to jurisdictional claims in published maps and institutional affiliations.
Abstract: This paper investigates how electrolytic plasma hardening (PEH) bears upon the changes in the phase structural and tribological properties of steel $0.34 \mathrm{C}-1 \mathrm{Cr}-1 \mathrm{Ni}-1 \mathrm{Mo}-\mathrm{Fe}$, which is widely used in manufacturing highly stressed gears. The samples of steel $0.34 \mathrm{C}-1 \mathrm{Cr}-1 \mathrm{Ni}-1 \mathrm{Mo}-\mathrm{Fe}$ went through the $\mathrm{PEH}$ in an electrolyte containing an aqua solution of $20 \%$ calcined soda $\left(\mathrm{Na}_{2} \mathrm{CO}_{3}\right)$ and $10 \%$ carbamide $\left(\left(\mathrm{NH}_{2}\right)_{2} \mathrm{CO}\right)$. The initial steel $0.34 \mathrm{C}-1 \mathrm{Cr}-1 \mathrm{Ni}-1 \mathrm{Mo}-\mathrm{Fe}$ is stated to have the following structural components: a lamellar pearlite with volume share of $35 \%$, a ferrite-carbide mixture of $\sim 45 \%$ and a fragmented ferrite of $\sim 20 \%$; after the PEH it contains lath-lamellar martensite, fine particles of cementite and $\mathrm{M}_{23} \mathrm{C}_{6}$ carbide. The durability of steel $0.34 \mathrm{C}-1 \mathrm{Cr}-1 \mathrm{Ni}-1 \mathrm{Mo}-\mathrm{Fe}$ was found to rise by 3.4 times after the $\mathrm{PEH}$ and its microhardness increased in 2.6 times. The curve-tension of the crystal lattice was established to be like plastic $\left(\chi=\chi_{\mathrm{pl}}\right)$ and does not cause the formation of microcracks in the material.

Keywords: electrolytic-plasma hardening (PEH); modified layer; phase composition; microhardness; wear-resisting properties; durability

\section{Introduction}

The continuous improvement of the operational characteristics of modern machines-along with their basic units and parts, equipment and facilities-is known to be provided by increasing their capacity and performance, which requires intensively improving the performance of these machines and parts [1]. The industry constantly requires the improvement and intensification of the working and operational characteristics of modern equipment (including the equipment, parts and their node), which is provided by increasing their power and productivity. In addition, using modern hardening technologies, the operational characteristics of the parts' working surfaces are improved, leading to an increase in the equipment's service life. The conditions of the working surface layer, where damage is actively developing-and thereby shortens the service life of any equipment's part-provides an assessment of the technical and economic indicators of an equipment's operation. To ensure a high cyclic durability, high wear resistance, and reduced sensitivity to stress concentrators, it is necessary to create a gradient of properties in the hardened section of a part that provides a hard and wear-resistant surface, a viscous but strong core, and compressive stresses in the surface layer [2,3]. This all becomes possible if we apply the method of surface hardening. 
The on-site surface hardening of wearing surfaces, combined with several other techniques, is today considered promising, alongside metallurgical techniques and surface hardening, in the conditions of manufacturers to increase the service life of gears. The surface hardening of steel parts is one of the most efficient and forceful ways to increase the service life of the loaded elements of machines and mechanisms, as well as to reduce their material consumption. At the same time, only the most loaded working surface of the part is strengthened, leaving the core intact [4]. At the same time, progress in improving the quality of tempering (hardening) of the working surfaces of parts is associated with the use of concentrated energy sources: electron beams, laser beams and plasma jets. Such methods allow higher performance properties and quality of hardening to be achieved.

High-frequency, gas flame, plasma, electron beam and laser processing are widely used in industry for the surface hardening of gears [5]. Existing strengthening techniques are widely and effectively applied in manufacturing according to their technical and economic indicators [6-8]. Plasma electrolytic hardening (PEH) is one type of plasma surface hardening. The main distinctive features of the PEH method are its lower cost, greater availability of process equipment and consumables, larger area of the hardened zone and a higher cooling rate compared to conventional methods of plasma surface hardening. The idea behind this method is in the thermal phase and structural transformations that take place during the rapid, concentrated heating of the working surface of the part by plasma action, which is followed by rapid cooling due to heat transfer to the part material [9]. The quenching-type structures formed by this method have a high hardness, wear resistance and rupture strength.

By improving the characteristics of the material, $\mathrm{PEH}$ allows more efficient structures to be made that decrease the equipment's weight, increase the service life of its components and increase its productivity. An effective method for reducing the weight is to increase the strength of the materials. Unlike the method of increasing stresses by reducing the actual strength reserve related to the risk of a weakening of the part, the reliability in this case does not decrease (i.e., if the value of the strength reserve is maintained). This method works for all parts without exception, whereas the method of increasing stresses is applicable only to design parts.

In view of this fact, the purpose of this paper is to investigate how plasma-electrolytic hardening influences the phase-structural conditions and mechanical and tribological properties of $0.34 \mathrm{C}-1 \mathrm{Cr}-1 \mathrm{Ni}-1 \mathrm{Mo}-\mathrm{Fe}$ steel.

\section{Materials and Methods}

Steel $0.34 \mathrm{C}-1 \mathrm{Cr}-1 \mathrm{Ni}-1 \mathrm{Mo}-\mathrm{Fe}$ was chosen as a subject according to the study's goal. This choice is explained by the fact that this steel is widely used in manufacturing highly stressed gears.

Steel samples underwent plasma electrolytic hardening in a machine consisting of a source of power, a PEH chamber and a computer [10]. Figure 1 illustrates the sequence of the PEH process. The chemical composition of the steel studied is provided by the commercial TU 24-1-12-179-75 characteristics, but the measured chemical composition of the studied steel also include: C: $0.3-0.4 \%$; Si: $0.17-0.37 \%$; Mn: $0.5-0.8 \%$; Ni: $1.3-1.7 \%$; Cr: $1.3-1.7 \%$; Mo: $0.2-0.3 \%$; S: up to $0.035 \%$; P: up to $0.03 \%$.

A sodium-carbonate-based electrolyte was chosen for conducting PEH. Carbamide was added to the electrolyte to prevent decarbonizing. Carbamide was chosen because it is a source of carbon and is cheap and environment-friendly. In addition, sodium carbonate interacts well with carbamide. Therefore, $\mathrm{PEH}$ was performed in an electrolyte containing an aqua solution of $20 \%$ calcined soda $\left(\mathrm{Na}_{2} \mathrm{CO}_{3}\right)$ and $10 \%$ carbamide $\left(\left(\mathrm{NH}_{2}\right)_{2} \mathrm{CO}\right)$.

The PEH of steel samples was carried out as follows: the bath (6) was filled with electrolyte; the electrolyte was fed by a pump (4) to the cone-shaped nozzle (3), while the electrolyte jet flowed out through the hole, drained over the edge into the bath (6) and came back into the cone-shaped nozzle. Thus, the electrolyte was constantly in the circulation mode. The electrolyte feed rate (flow rate) was $5-7 \mathrm{~L} / \mathrm{min}$. A processed 
sample was immersed in the electrolyte by means of a holding mechanism so that the processed area of the sample was located at a distance of 2-3 $\mathrm{mm}$ from the opening of the cone-shaped nozzle. At the same time, an electrolyte jet was supplied to the processed area through the opening in the cone-shaped nozzle located 10-15 $\mathrm{mm}$ below the top edge of the dividing wall. An anode (2) was connected to the positive pole of the power supply, and a processed sample_cathode (1)—was connected to its negative pole. A voltage of $320 \mathrm{~V}$ was supplied between the electrodes for $2 \mathrm{~s}$ to heat the electrolyte to the quenching temperature (800-900 ${ }^{\circ} \mathrm{C}$ ); the current density here was $25-30 \mathrm{~A} / \mathrm{cm}^{2}$. Under these stresses, an intensely luminous plasma layer was formed in the near-cathode region and the sample was heated at a velocity of $400-500{ }^{\circ} \mathrm{C} / \mathrm{s}$. In such a case, an abnormal arc discharge is formed between the electrodes, resulting in a rapid heating of the in-process part [11].

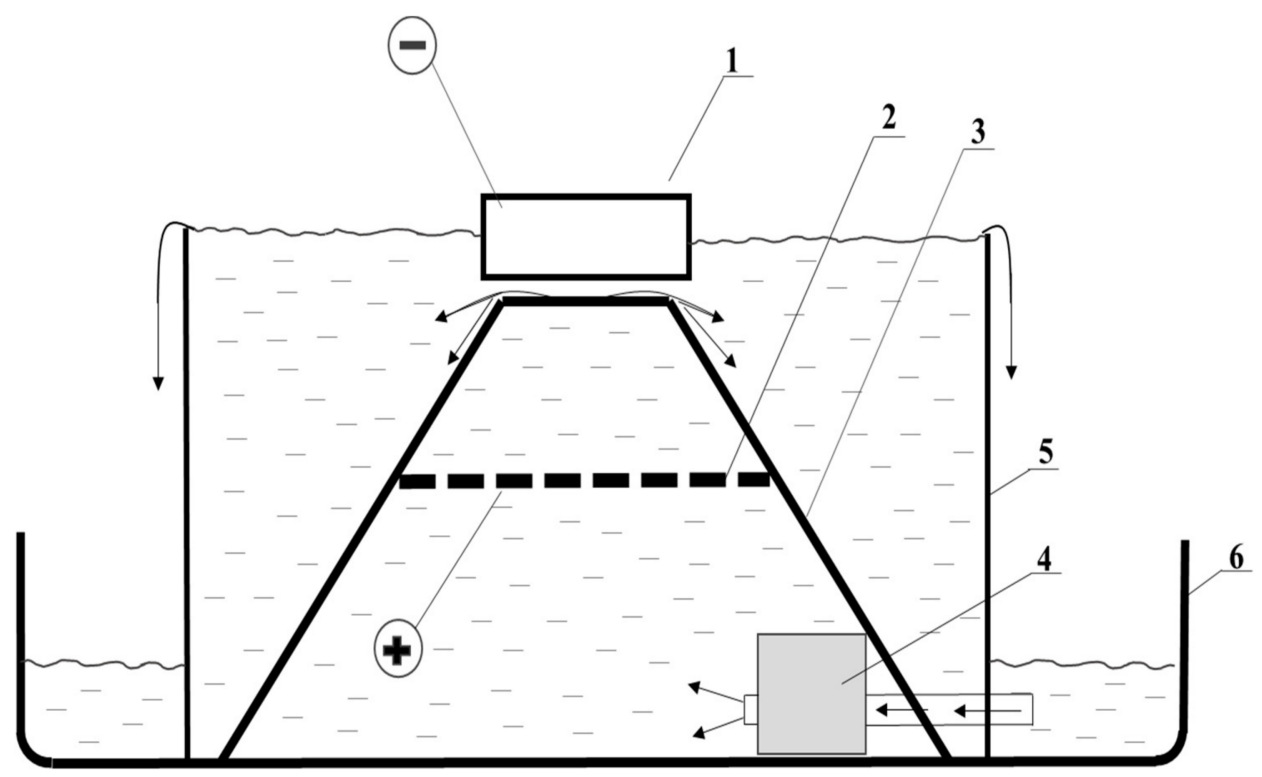

Figure 1. The sequence of the samples' PEH. 1-sample (cathode), 2-anode, 3-conic nozzle, 4 -pump, 5-divide wall, 6-bath.

The NEOPHOT-21 optical microscope was used to study general metal structure characteristics. Metallographic cuts of the steel samples were prepared following the techniques described in paper [12]. Morphological and elemental analysis of the samples processed in electrolytic plasma was obtained using a scanning electron microscope JSM-6390LV (JEOL, Japan) with an INCAEnergy add-on device for energy dispersion microanalysis (OXFORD Instruments). X-ray diffraction studies of the steel samples were performed through standard X-ray diffraction analysis methods using $X^{\prime}$ PertPRO diffractometers. Diffractogram videos were taken using $\mathrm{CuK} \alpha$-radiation $\left(\lambda=2.2897 \mathrm{~A}^{0}\right)$ at a voltage of $40 \mathrm{kV}$ [13]. Fine structure morphology was studied using an EM-125 electron microscope with an accelerating voltage of $125 \mathrm{kV}$. Working magnification in the column of the microscope was chosen to be from 8000 to 50,000 times.

The microhardness of the steel samples was measured in the PMT-3 device in accordance with GOST 9450-76, under the loads on the indenter $\mathrm{P}=1 \mathrm{~N}$ and a holding time of $10 \mathrm{~s}$ [14]. For the samples, the nanohardness of coatings was determined by the OliverPharr method using the nanoidentation system with the Berkovich indenter at a load of $100 \mathrm{mN} / \mathrm{g}$ and a holding time of $5 \mathrm{~s}$. Tribological tests for the sliding friction were performed on a high-temperature tribometer THT-S-BE-0000 using the standard ball-disk technique according to the international standards ASTM G 133-95 and ASTM G 99. A ball with a diameter of $6.0 \mathrm{~mm}$ and made of a certified material $\left(\mathrm{Al}_{2} \mathrm{O}_{3}\right)$ was used as a counterweight. Tests were performed at a load of $1 \mathrm{~N}$ and a linear velocity of $2 \mathrm{~cm} / \mathrm{s}$, and with a wear radius of $6 \mathrm{~mm}$ and a friction path of $25 \mathrm{~m}$. Tribological characteristics of the modified layer were evaluated by the wear intensity, wear volume and friction coefficient. 
Strength characteristics of the steel samples were determined through mechanical tensile testing at room temperature. Mechanical tests were performed in a universal testing machine WDW-5E in accordance with the requirements of GOST 1497-87 for steel 0.34C$1 \mathrm{Cr}-1 \mathrm{Ni}-1 \mathrm{Mo}-\mathrm{Fe}$. The tests were laid in a uniaxial static stretching of the flat samples up to their rupture with measuring conditional yield strength $\sigma_{0.2}$, fracture strength $\sigma_{B}$ and relative elongation to rupture $\delta$.

\section{Results and Discussion}

\subsection{Structure and Morphology}

The structural phase conditions of the hardened steel surface layers $0.34 \mathrm{C}-1 \mathrm{Cr}-1 \mathrm{Ni}-$ $1 \mathrm{Mo}-\mathrm{Fe}$ were investigated before and after PEH. According to the optico-metallographic analysis, the initial structure of steel $0.34 \mathrm{C}-1 \mathrm{Cr}-1 \mathrm{Ni}-1 \mathrm{Mo}-\mathrm{Fe}$ is similar to the ferrite-pearlite structure (Figure 2a), but there are many more pearlite grains with a cementite network at their borders than there is ferrite. The hardening of $0.34 \mathrm{C}-1 \mathrm{Cr}-1 \mathrm{Ni}-1 \mathrm{Mo}-\mathrm{Fe}$ surface layers with the PEH technique resulted in the formation of a fine martensite structure (Figure $2 b$ ).
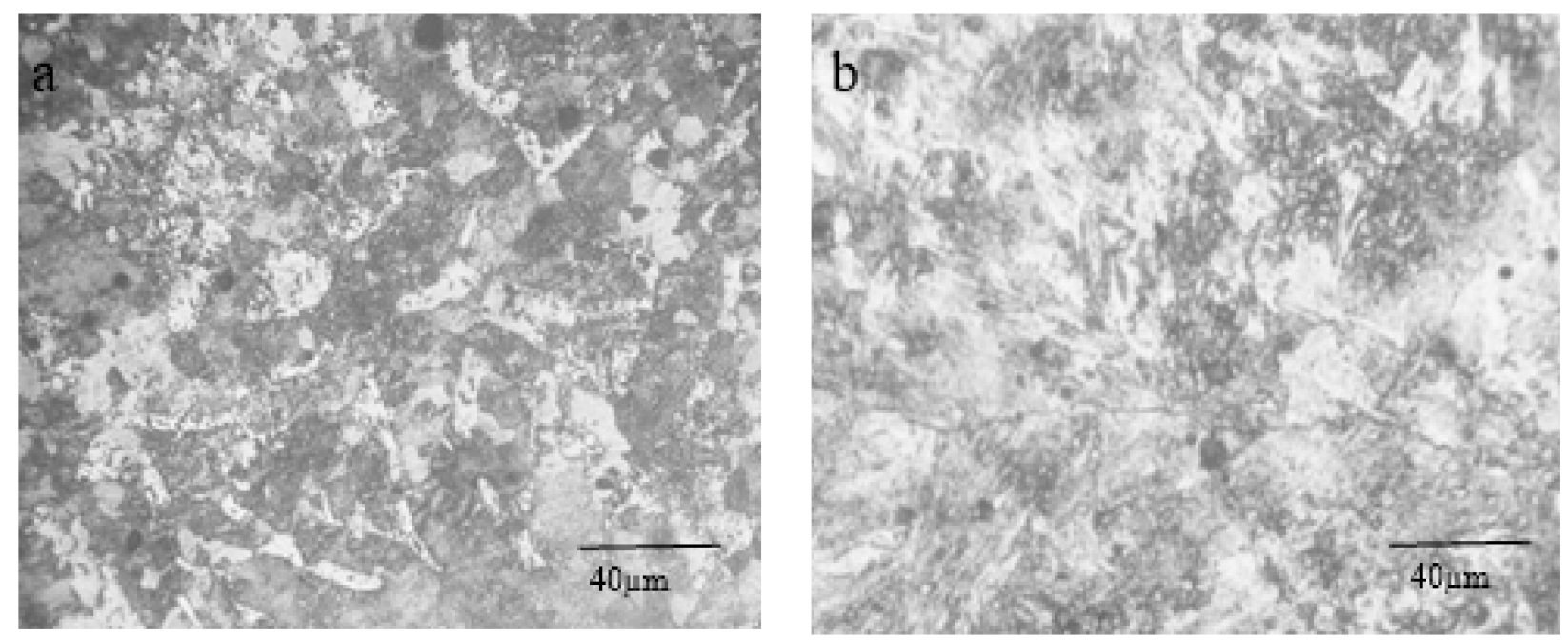

Figure 2. Microstructure of the surface of a $0.34 \mathrm{C}-1 \mathrm{Cr}-1 \mathrm{Ni}-1 \mathrm{Mo}-\mathrm{Fe}$ sample before and after the PEH. (a) $-0.34 \mathrm{C}-1 \mathrm{Cr}-1 \mathrm{Ni}-$ 1Mo-Fe initial state, (b)-0.34C-1Cr-1Ni-1Mo-Fe after PEH.

Figure 3 shows X-ray diffractograms of $0.34 \mathrm{C}-1 \mathrm{Cr}-1 \mathrm{Ni}-1 \mathrm{Mo}-\mathrm{Fe}$ steel before and after the PEH. The X-ray diffraction analysis showed that the initial structure of $0.34 \mathrm{C}-1 \mathrm{Cr}-$ $1 \mathrm{Ni}-1 \mathrm{Mo}-\mathrm{Fe}$ steel consisted of an $\alpha$-phase. After the PEH, there were $\alpha$-phase reflexes broadening that indicate the formation of martensite. After the PEH, cementite and a small amount of austenite were also formed. The formation of residual austenite was associated with a high cooling rate, and polymorphic transformations did not have enough time to occur. The metallographic analysis showed that there was cementite in the initial state of the steel structure, but the X-ray spectral analysis (XRS) did not detect any cementite in the initial state. This was due to the low content of cementite in the initial state. One of the disadvantages of XRS is the low amplitude of the X-ray scattering of light atoms such as hydrogen, carbon, oxygen, etc., which implies a weak sensitivity to them, especially compared to heavy atoms. 


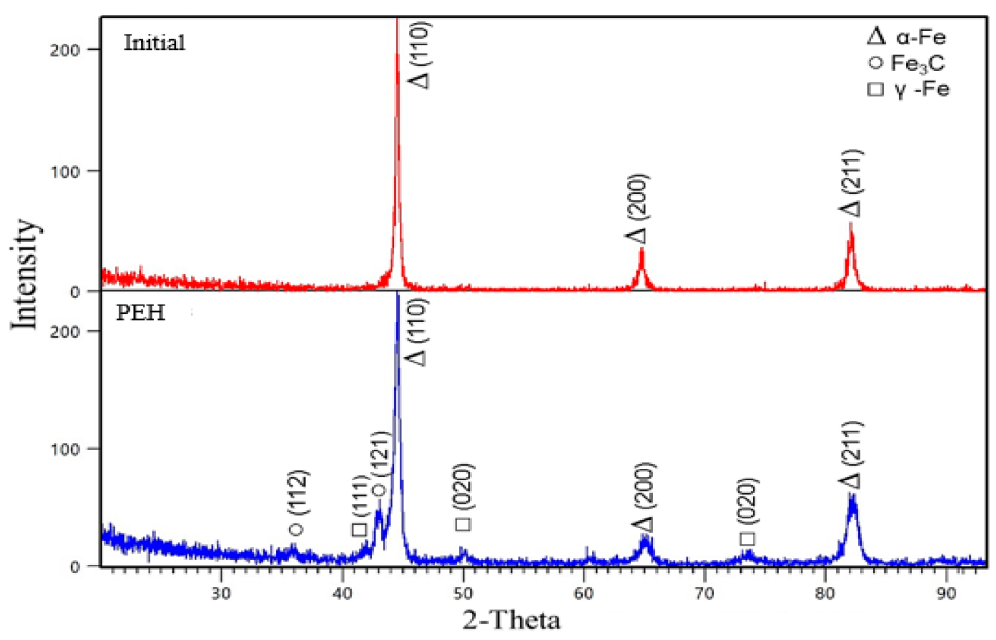

Figure 3. X-ray diffractogram of the $0.34 \mathrm{C}-1 \mathrm{Cr}-1 \mathrm{Ni}-1 \mathrm{Mo}-\mathrm{Fe}$ steel samples before and after the PEH.

According to numerous studies [15] the formation of a modified surface layer with a phase structural component constituted by fine grained martensite with residual austenite will positively affect the tribological properties of spare parts.

Figure 4 shows fragments of a microstructure obtained using the Scanning electron microscope, a cross section of $0.34 \mathrm{C}-1 \mathrm{Cr}-1 \mathrm{Ni}-1 \mathrm{Mo}-\mathrm{Fe}$ steel in the course of the $\mathrm{PEH}$, where the zonality of the structure is observed that is typical for surface hardening. The PEH of the steel led to the modification of the sample's surface layer. The layer structure changed as it moved away from the sample's surface. The image of the cross-section microchip shown in Figure 4 was taken using the Scanning electron microscope at a relatively small magnification. It can be seen that a modified surface layer consisting of martensite with an average thickness of $\sim 1.7-2 \mathrm{~mm}$ is clearly distinguished on the cross-section of the microchip. Then, moving depthward down the sample we can see a transition layer followed by the layer (zone) of the main material.
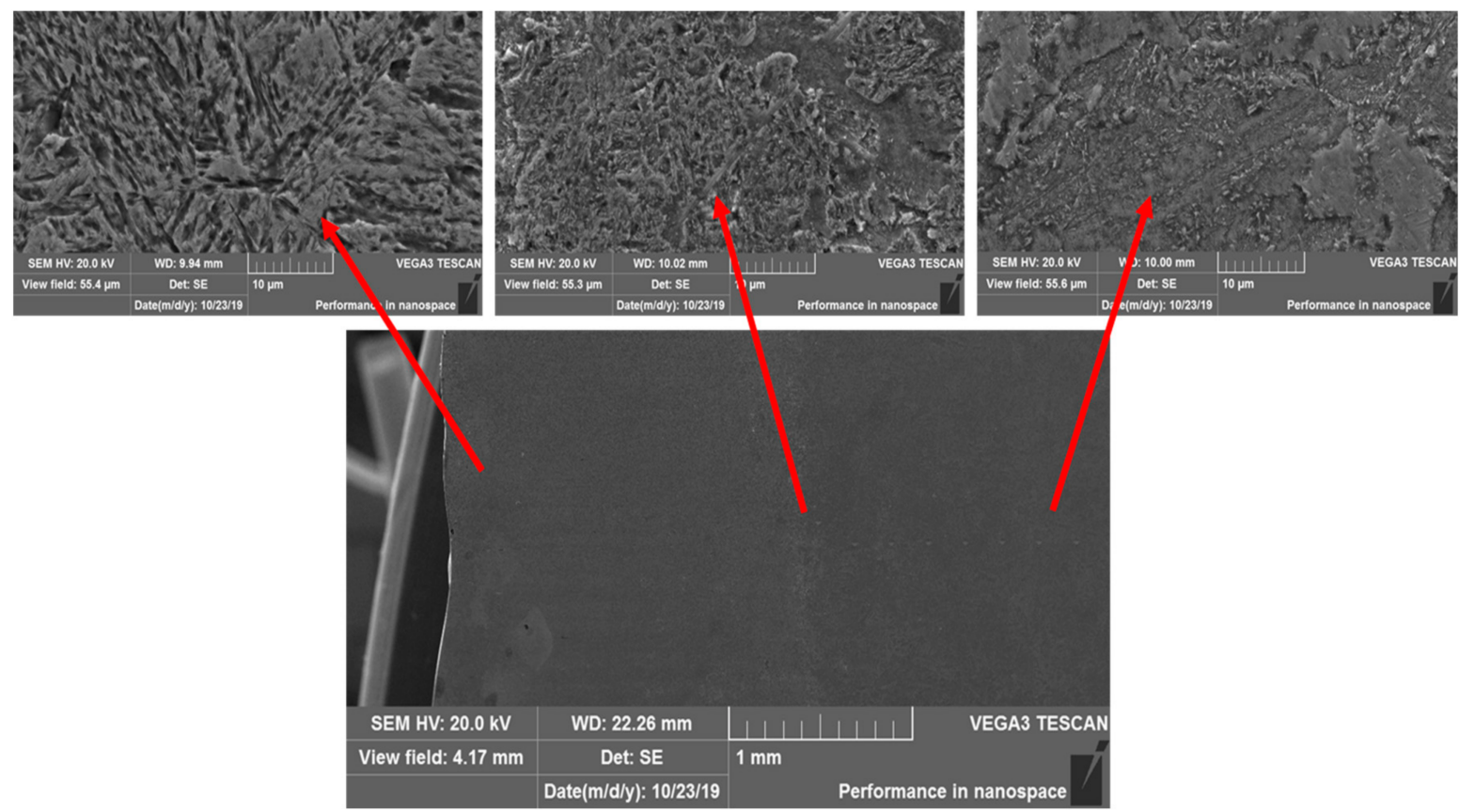

Figure 4. Cross-section of the PEH sample, and photomicrographs from the surface (left) to bulk material (right). 
Figure 5 shows the chemical composition of the modified surface layer through the depth of the steel $0.34 \mathrm{C}-1 \mathrm{Cr}-1 \mathrm{Ni}-1 \mathrm{Mo}-\mathrm{Fe}$ obtained using the EDS analysis. Based on the results regarding the depth, it can be stated that carbon atoms were collected on the surface of modified layer. That is due to the fact that the PEH process took place in an electrolyte containing aqua solution of $20 \%$ sodium carbonate and $10 \%$ carbamide where the surface was saturated with carbon.
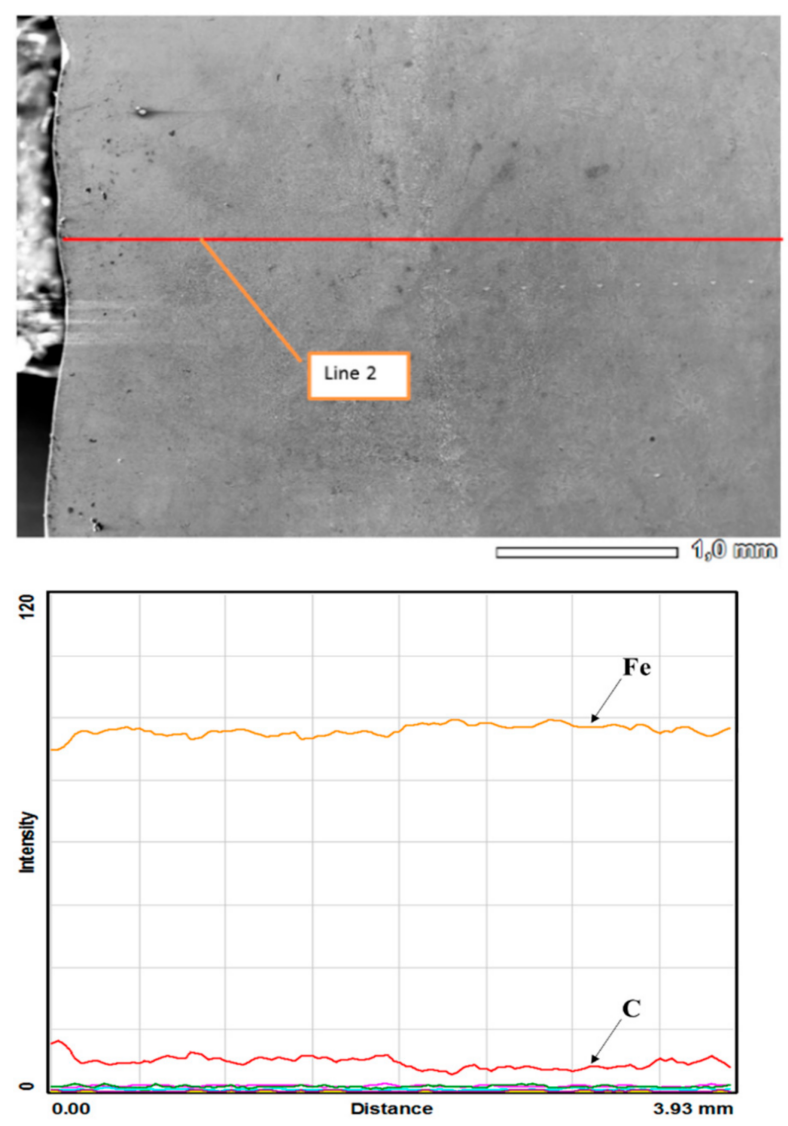

Figure 5. EDS analysis of the modified surface layer through the depth of a $0.34 \mathrm{C}-1 \mathrm{Cr}-1 \mathrm{Ni}-1 \mathrm{Mo}-\mathrm{Fe}$ steel sample.

The results of the transmission electron microscopy of the initial steel structure confirmed the data from the XRS and metallographic analysis. According to this research and the images of the fine structure obtained using the electron microscopic analysis, the initial state of the $0.34 \mathrm{C}-1 \mathrm{Cr}-1 \mathrm{Ni}-1 \mathrm{Mo}-\mathrm{Fe}$ steel structure consisted of lamellar pearlite, a ferritocarbide mixture and fragmented ferrite. An electron microscope image of the lamellar pearlite in the $0.34 \mathrm{C}-1 \mathrm{Cr}-1 \mathrm{Ni}-1 \mathrm{Mo}-\mathrm{Fe}$ steel is shown in Figure 6. The volume fraction of the pearlite in the initial state of the $0.34 \mathrm{C}-1 \mathrm{Cr}-1 \mathrm{Ni}-1 \mathrm{Mo}-\mathrm{Fe}$ steel was $35 \%$, and the volume fractions of the ideal perlite and fragmented pearlite were $10 \%$ and $25 \%$, respectively. The volume fraction of the second component of the structure-the ferritocarbide mixture-was $\sim 45 \%$. The average scalar density of the dislocations inside the fragments of the $\alpha$-phase was $2.25 \times 10^{10} \mathrm{~cm}^{-2}$. The volume fraction of the third component of the structure-fragmented ferrite-was $20 \%$ of the material. The average scalar density of the dislocations inside the fragments of the $\alpha$-phase was $2.95 \times 10^{10} \mathrm{~cm}^{-2}$. 


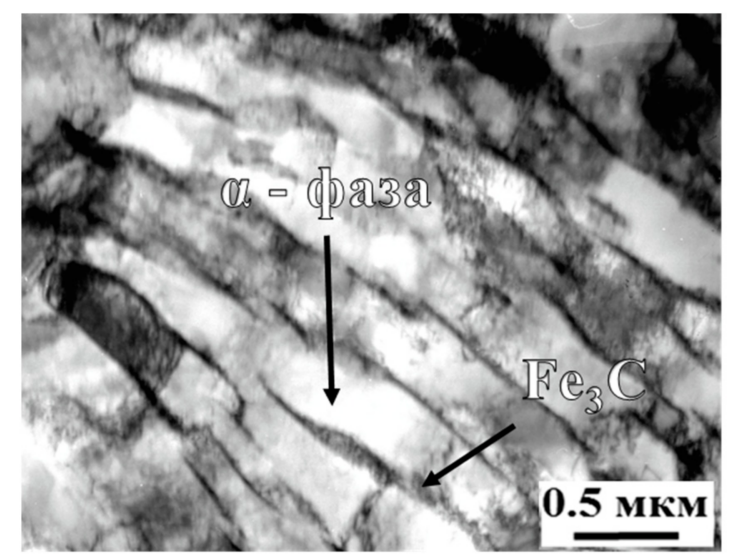

Figure 6. Electron-microimage of the $0.34 \mathrm{C}-1 \mathrm{Cr}-1 \mathrm{Ni}-1 \mathrm{Mo}-\mathrm{Fe}$ steel in its initial state.

The results of the transmission electron microscopy of the steel after the PEH showed that the structure contained $\mathrm{M}_{23} \mathrm{C}_{6}$ carbide along with martensite, cementite and residual austenite. Figure 7 provides an electron microimage of the thin structure of the hardened steel surface layer that shows the allocation of the $\mathrm{M}_{23} \mathrm{C}_{6}$ carbide (marked with letter $\mathrm{K}$ near the indicated reflexes) in the sublayers of the residual austenite located at the boundaries of the martensitic lamellae. The arrows in Figure $7 \mathrm{~b}$ indicate the matching directions: (1) $[\overline{111}]_{\gamma}$ II [ $\left.0 \overline{2} 1\right]_{\alpha}$, wherein the assumption is performed $(112)_{\gamma}$ II $(012)_{\alpha}$-the Kurdyumov-Sachs orientation relation; and (2) [ $1 \overline{1} 0]_{\gamma} I I[3 \overline{1} 0]_{\mathrm{K}}$, wherein the assumption is performed $(112)_{\gamma} I I(131)_{\mathrm{K}}$-the cube-cube orientation relation.

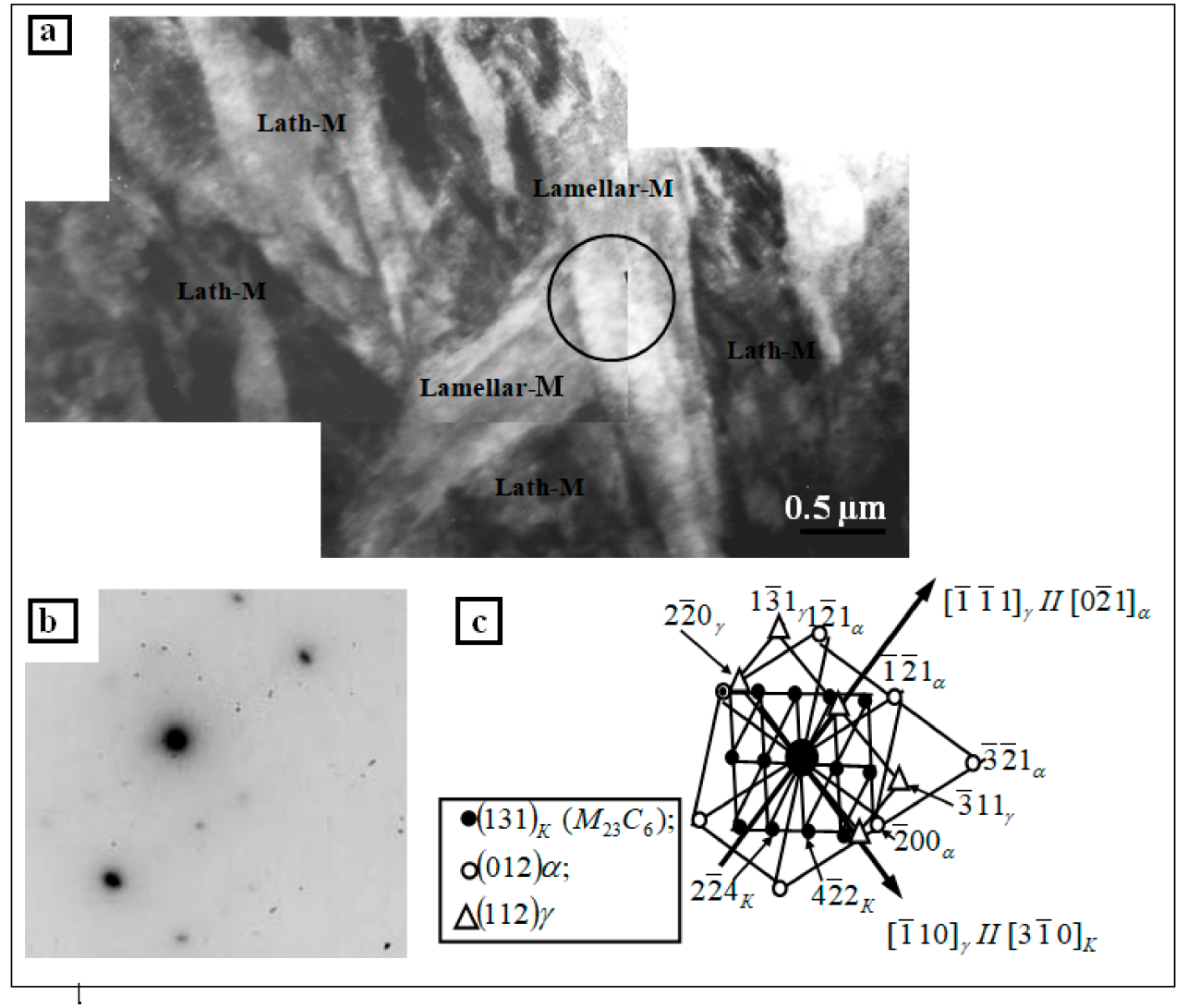

Figure 7. Electron microimage of $0.34 \mathrm{C}-1 \mathrm{Cr}-1 \mathrm{Ni}-1 \mathrm{Mo}-\mathrm{Fe}$ steel after $\mathrm{PEH}$. (a) - light field image; (b)-microdiffraction picture taken in the region marked on (a) with a circle; (c) -its indicated scheme. 
During the bending-torsion of a crystal lattice, the amplitude of the internal stresses was calculated. It turned out that $\sigma_{\mathrm{d}}=285 \mathrm{MPa}$ in the lath martensite, $\sigma_{\mathrm{d}}=270 \mathrm{MPa}$ in the lamellar martensite and $\sigma_{\mathrm{d}}=280 \mathrm{MPa}$ throughout the material.

One more type of internal stress, called shear stresses $\sigma_{\mathrm{L}}$ (stresses created by dislocation structure), is known to be present when a defective structure is represented by dislocations in a material. The calculations show that $\sigma_{\mathrm{L}}=390 \mathrm{MPa}$ in the lath martensite, $\sigma_{\mathrm{L}}=345 \mathrm{MPa}$ in the lamellar martensite and $\sigma_{\mathrm{L}}=370 \mathrm{MPa}$ throughout the material.

It can be seen, first, that all quantitative parameters in the lath martensite were higher than in the lamellar martensite. Secondly, the following conditions are met along the material after the surface hardening, as in the initial state: $\rho>\rho_{ \pm} и \sigma_{L}>\sigma_{д}$. This means that the bending-torsion (distortion) of the crystal lattice of the $0.34 \mathrm{C}-1 \mathrm{Cr}-1 \mathrm{Ni}-1 \mathrm{Mo}-\mathrm{Fe}$ steel after PEH was also purely plastic, which will not lead to the formation of microcracks in the material.

\subsection{Mechanical and Tribological Properties}

The modification of the tribological and mechanical properties of structural steel $0.34 \mathrm{C}$ $1 \mathrm{Cr}-1 \mathrm{Ni}-1 \mathrm{Mo}-\mathrm{Fe}$ before and after it has undergone the $\mathrm{PEH}$ have been experimentally studied. Figure 8 shows results of the tribological tests of the $0.34 \mathrm{C}-1 \mathrm{Cr}-1 \mathrm{Ni}-1 \mathrm{Mo}-\mathrm{Fe}$ samples according to the ball-on-disk technique. The wear resistance of the samples was characterized by the intensity of the wear and the volume of the wear on the steel samples $0.34 \mathrm{C}-1 \mathrm{Cr}-1 \mathrm{Ni}-1 \mathrm{Mo}-\mathrm{Fe}$ before and after the PEH. Figure 8 shows that the processed samples had a low wear rate compared to the initial sample. Figure $8 \mathrm{~b}$ illustrates that after PEH the samples wore down very little compared to the initial samples, which demonstrated the higher wear resistance of the steel after the PEH.
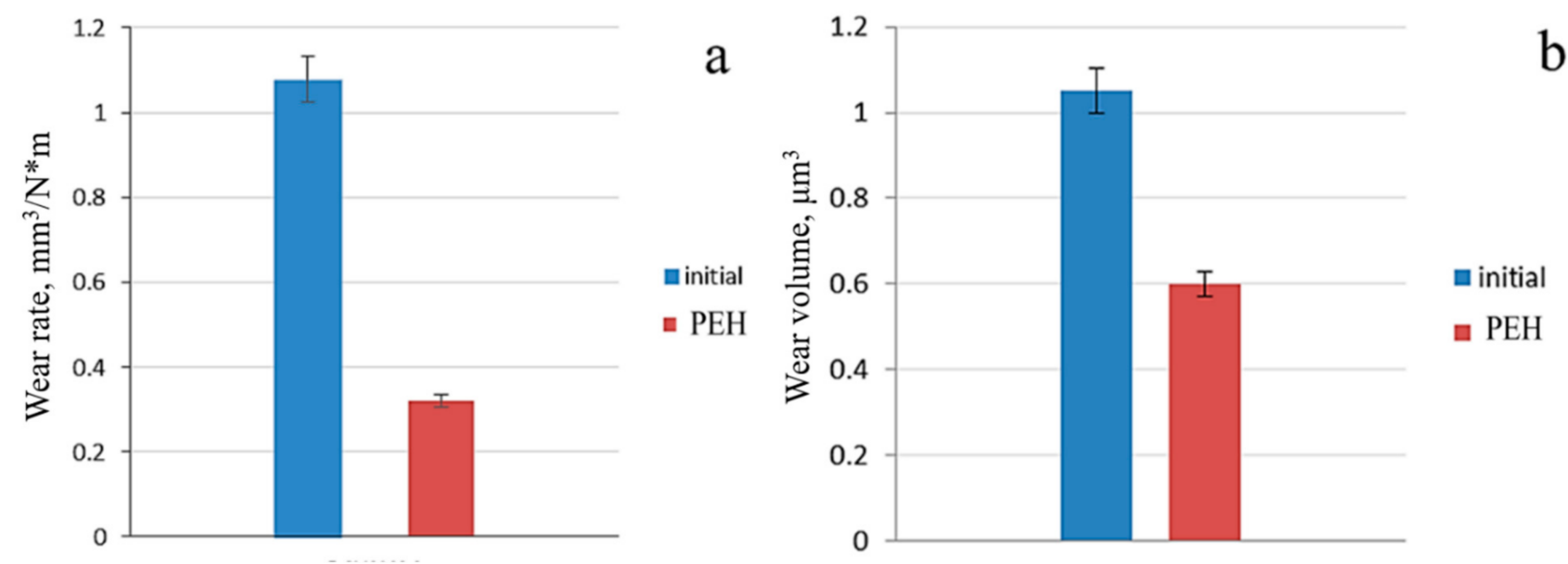

Figure 8. Wear rate (a) and wear volume (b) of steel $0.34 \mathrm{C}-1 \mathrm{Cr}-1 \mathrm{Ni}-1 \mathrm{Mo}-\mathrm{Fe}$ before and after the PEH.

For parts of this functional purpose, wear resistance is an important operational property. The level of wear resistance affects both the performance of structures as a whole and the preservation of the geometric sizes of individual parts. The results of tribological tests have shown that the electrolyte-plasma hardening has a significant effect on wear resistance.

According to the results of X-ray phase analysis and TEM studies, an increase in the wear resistance of the surface layer of steel is related to the formation of a modified surface layer with a phase structural component of fine grained martensite with residual austenite.

The intensity of wear under the influence of the tip is calculated based on the volume of material displaced during the test, which was calculated using the following formula:

$$
\mathrm{I}=\frac{\mathrm{V}}{\mathrm{F} * 1},
$$


where: $I$ iswear intensity $\left[\mathrm{mm}^{3} / \mathrm{N}^{*} \mathrm{~m}\right] ; 1$ is the friction path, $[\mathrm{m}] ; \mathrm{F}$ is the nominal pressure $[\mathrm{H}]$; and $\mathrm{V}$ is the volume of the wear part $\left[\mathrm{mm}^{3}\right]$. As a result of the calculations, data on the wear intensity for the samples before and after the PEH were obtained.

Images of the wear tracks of the $0.34 \mathrm{C}-1 \mathrm{Cr}-1 \mathrm{Ni}-1 \mathrm{Mo}-\mathrm{Fe}$ steel samples were taken using a profile meter (Figure 9). When evaluating the samples' wear resistance based on the geometric parameters of the wear tracks we can say that the depth of the sample track after the PEH (Figure 9b) was significantly smaller than that of the initial samples (Figure 9a). The shape of the unevenness generally once again demonstrates improved tribological properties in the testing sample. Figure 9c shows a graph of the behavior of the friction coefficient in the course of the experiment. The measurements showed minor changes in the coefficient of friction. The surface roughness was measured using the Ra parameter using profilometer model 130 on a $7 \mathrm{~mm}$ long segment of the sample surface. From the data obtained, the value of the parameter Ra for the initial sample was 0.199 and after processing $\mathrm{Ra}=0.446$ [16].

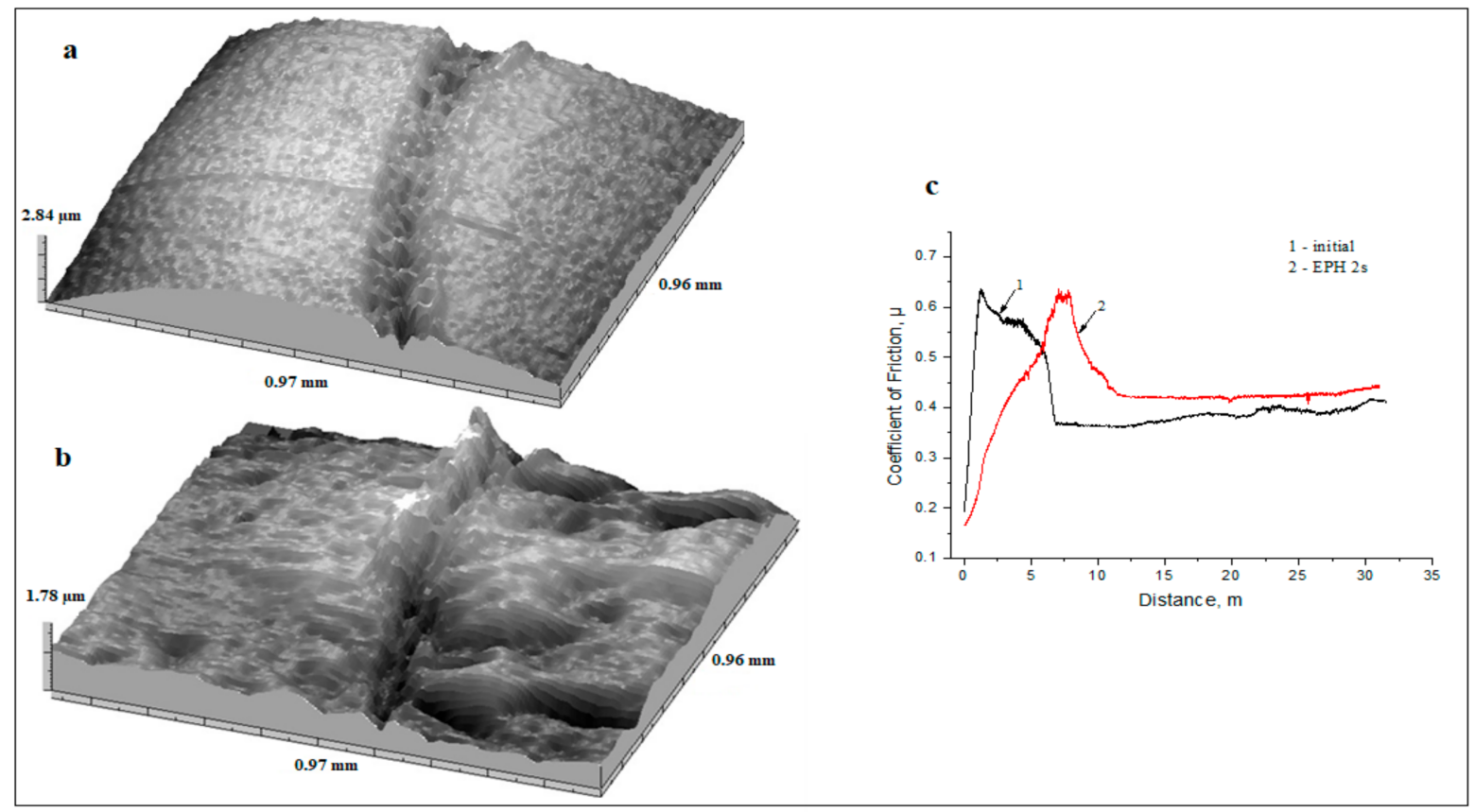

Figure 9. Fragment picture of the wear track and a graph of the behavior of the friction coefficient of the $0.34 \mathrm{C}-1 \mathrm{Cr}-$ 1Ni-1Mo-Fe steel samples: (a)—untreated sample, (b)—sample after the $\mathrm{PEH},(\mathbf{c})$ — graph of the change in the coefficient of friction.

Figure 10 shows a graph of the loading dependence on the extension of $0.34 \mathrm{C}-1 \mathrm{Cr}-$ $1 \mathrm{Ni}-1 \mathrm{Mo}-\mathrm{Fe}$ before and after the PEH. According to the results of the tensile test of $0.34 \mathrm{C}$ $1 \mathrm{Cr}-1 \mathrm{Ni}-1 \mathrm{Mo}-\mathrm{Fe}$ steel, the following parameter changes were obtained: the strength limit $\left(\sigma_{B}\right)$ in the initial state was $743 \mathrm{MPa}$; after PEH it increased to $835 \mathrm{MPa}$, i.e., by 1.12 times. There was the same change in the yield strength $\left(\sigma_{0.2}\right)$; in the initial state, it was $648 \mathrm{MPa}$, and after the PEH it was $740 \mathrm{MPa}$, which indicates an increase by 1.14 times in contrast to the initial state. The value of the relative elongation before the break $(\delta)$ in the initial state was $10 \%$ and after processing it increased to $13 \%$. 

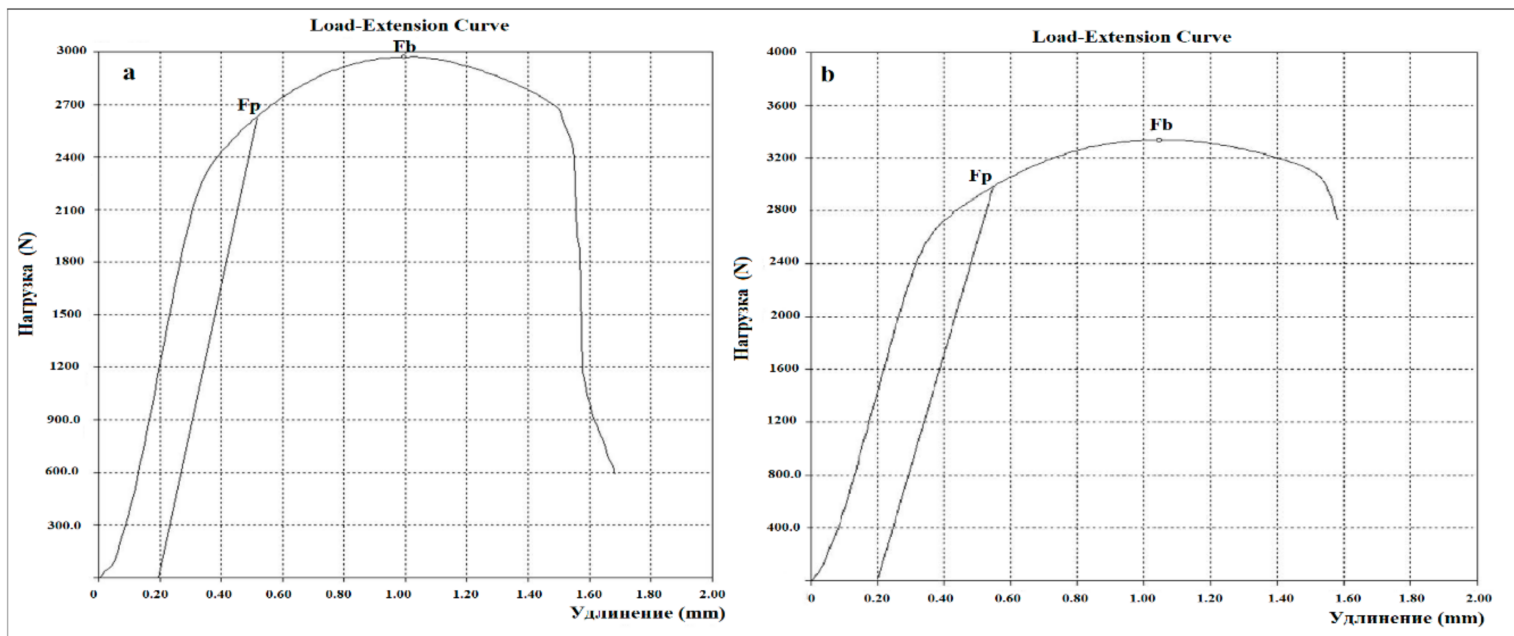

Figure 10. A graph of the loading dependence on the extension of the $0.34 \mathrm{C}-1 \mathrm{Cr}-1 \mathrm{Ni}-1 \mathrm{Mo}-\mathrm{Fe}$ steel samples before (a) and after (b) the PEH.

Figure 11 shows a graph of the change in microhardness through the depth of the sample treated by the PEH method. The microhardness data confirmed the formation of a martensitic structure. A significant increase in microhardness is seen near the surface. The transition zone displayed a smooth transition from the hardened layer to the basement, while the microhardness of the transition zone was slightly less than at the basement, and the microhardness of the basement did not change.

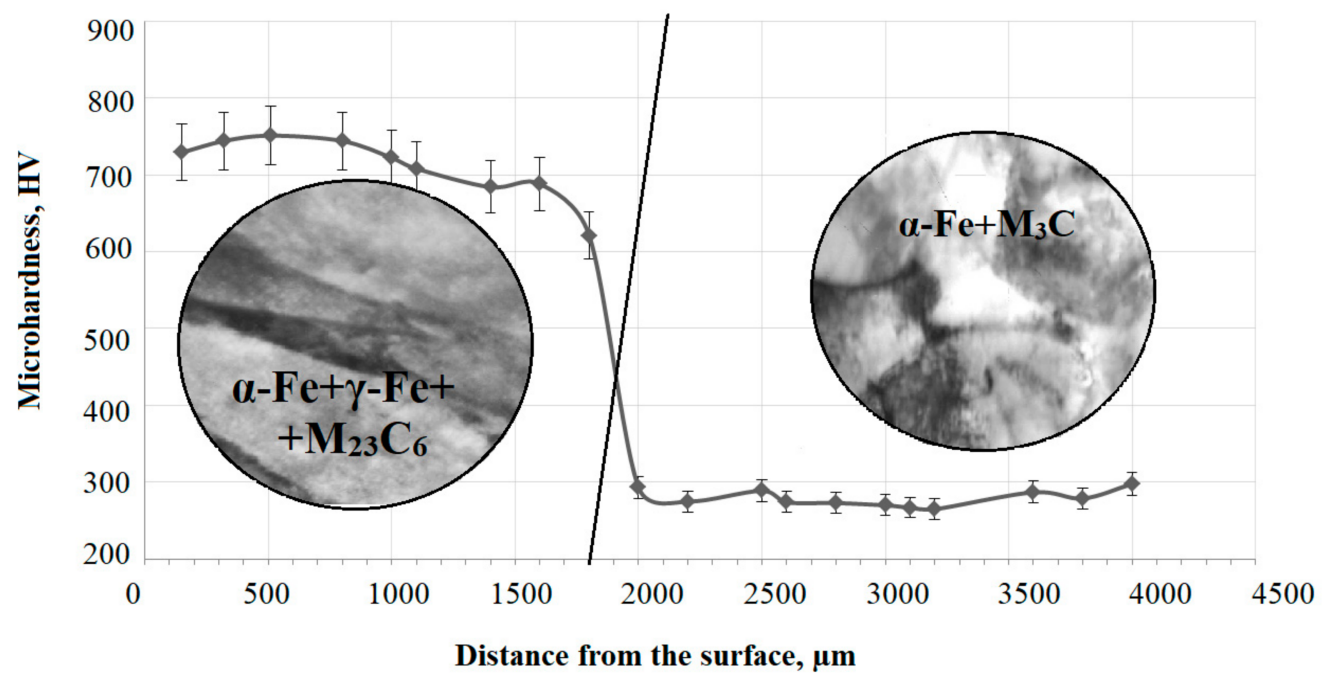

Figure 11. Diagram of the distribution of microhardness through the depth of the steel $0.34 \mathrm{C}-1 \mathrm{Cr}$ $1 \mathrm{Ni}-1 \mathrm{Mo}-\mathrm{Fe}$ samples after the PEH.

The results of the nanoindentation of the $0.34 \mathrm{C}-1 \mathrm{Cr}-1 \mathrm{Ni}-1 \mathrm{Mo}-\mathrm{Fe}$ steel samples before and after the PEH showed that the nanohardness of the sample after $\mathrm{PEH}$-determined by the loading diagram - was on average $8.12 \mathrm{GPa}$. This was 2.5 times more than the nanohardness of the initial sample.

According to earlier studies [17-19], most ferrite-perlite steels after electrolytic-plasma treatment usually have high wear resistance, microhardness, corrosion resistance and strength characteristics. A correct understanding of the mechanisms of strengthening the surface layer of steel during the PEH allows us to infer the structure of the layer and anticipate the changes that may occur in it depending on the nature of alloying. In this regard, the need to establish the main mechanisms of the electrolyte-plasma hardening to improve the performance of steel parts remains relevant. 
Table 1 provides data on the structure and tribological-mechanical characteristics of steel after the PEH. The experimental data clearly illustrate the correlation between the structural and tribological-technical characteristics of the hardened samples.

Table 1. Experimental data on the structure and tribological-mechanical behavior of steel $0.34 \mathrm{C}-1 \mathrm{Cr}-1 \mathrm{Ni}-1 \mathrm{Mo}-\mathrm{Fe}$.

\begin{tabular}{|c|c|c|c|c|c|c|c|c|c|}
\hline \multirow{2}{*}{ Material } & \multicolumn{9}{|c|}{ Characteristics } \\
\hline & Phase Composition & $\mathrm{H}_{\mu}, \mathrm{MPa}$ & $f$ & $\mathrm{j}, 10^{-4} \mathrm{~mm}^{3} / \mathrm{Nm}$ & $\mathrm{V}, \mu \mathrm{m}^{3}$ & $\sigma_{\mathrm{B}}, \mathrm{MPa}$ & $\sigma_{0.2}, \mathrm{MPa}$ & H, GPa & $\mathrm{E}, \mathrm{GPa}$ \\
\hline Initial state & $\alpha$-phase & 2830 & 0.44 & 1.08 & 1.05 & 743 & 648 & 2.88 & 242.33 \\
\hline After PEH, $2 \mathrm{~s}$ & $\alpha^{\prime}$-phase, $\gamma$-phase, $\mathrm{M}_{3} \mathrm{C}, \mathrm{M}_{23} \mathrm{C}_{6}$ & 7420 & 0.37 & 0.32 & 0.6 & 835 & 740 & 8.12 & 296.25 \\
\hline
\end{tabular}

From the generalized data given in Table 1 it can be seen that there was a significant increase in the tribological and mechanical properties of steel after the $\mathrm{PEH}$, which leads to the formation of $\alpha^{\prime}$-phase (martensite), $\gamma^{\prime}$-phase, $\mathrm{M}_{3} \mathrm{C}$ cementite and $\mathrm{M}_{23} \mathrm{C}_{6}$ carbide. Thus, it was found that as a result of the PEH, the surface layer of steel $0.34 \mathrm{C}-1 \mathrm{Cr}-1 \mathrm{Ni}-1 \mathrm{Mo}-\mathrm{Fe}$ had stronger microhardness and higher wear resistance. The increase in microhardness and wear resistance of $0.34 \mathrm{C}-1 \mathrm{Cr}-1 \mathrm{Ni}-1 \mathrm{Mo}-\mathrm{Fe}$ after $\mathrm{PEH}$ was particularly associated with the formation of martensite, as well as the formation of a defective substructure. A special role was given to fine particles of carbide phases. It is known from the papers $[20,21]$ that the effects of increasing hardness and wear resistance are directly related to the size and number of dispersed inclusions.

\section{Conclusions}

The following conclusions can be drawn from the analysis of the results obtained:

- Electrolytic-plasma hardening helps to improve the mechanical properties of $0.34 \mathrm{C}$ $1 \mathrm{Cr}-1 \mathrm{Ni}-1 \mathrm{Mo}-\mathrm{Fe}$ steel; namely, the microhardness increases by 2.6 times, and the strength limit $\sigma_{\mathrm{B}}$ and yield strength $\sigma_{0.2}$ increase to $835 \mathrm{MPa}$ and $740 \mathrm{MPa}$, respectively, compared to those of the initial sample, which were $743 \mathrm{MPa}$ and $648 \mathrm{MPa}$;

- The PEH improves the tribological properties of steel: the wear rate $\mathrm{j}$ of steel $0.34 \mathrm{C}$ $1 \mathrm{Cr}-1 \mathrm{Ni}-1 \mathrm{Mo}-\mathrm{Fe}$ is equal to $0.32 \mathrm{~mm}^{3} / \mathrm{Nm}$ after the $\mathrm{PEH}$; that is, 3.4 times less than the wear rate of the initial steel;

- $\quad$ The PEH leads to the formation of a modified layer consisting of an $\alpha^{\prime}$-phase (packet plate martensite), a $\gamma^{\prime}$-phase, small particles of cementite $\mathrm{M}_{3} \mathrm{C}$ and uniformly arranged in the volume of the $\mathrm{M}_{23} \mathrm{C}_{6}$ carbide material;

- Strengthening the microhardness and wear resistance of $0.34 \mathrm{C}-1 \mathrm{Cr}-1 \mathrm{Ni}-1 \mathrm{Mo}-\mathrm{Fe}$ steel is associated with the formation of martensite, as well as the formation of a defective substructure.

Author Contributions: Conceptualization, B.R.; methodology, B.R.; formal analysis, Z.S. (Zhuldyz Sagdoldina), G.Y., A.S., Y.I.; investigation, Z.S. (Zarina Satbayeva) G.Y., A.S., Y.I., writingoriginal draft preparation, B.R., Z.S. (Zarina Satbayeva), Z.S. (Zhuldyz Sagdoldina); writing-review and editing, B.R., Z.S. All authors have read and agreed to the published version of the manuscript.

Funding: This research was funded by the Ministry of Education of the Republic of Kazakhstan, grant number AP09058547.

Conflicts of Interest: The authors declare no conflict of interest.

\section{References}

1. Safonov, E.N. Plasma Hardening of Machine Parts: Monograph; NTI (branch) of UFU: Nizhny Tagil, Russia, $2014 ;$ p. 116.

2. Bolshakova, M.Y.; Guzanov, B.N.; Migacheva, G.N. Probabilistic Method for Calculating the Durability of Heavy-Load Gears According to the Wear Criterion; Theory and technology of metallurgical production: Mezhregion, collection of scientific papers; Kolokoltsev, V.M., Ed.; Publishing house SEI HVE MSTU: Magnitogorsk, Russia, 2010; Volume 10, pp. 193-204.

3. Medelyaev, N.A. Basic regularities of the processes of friction and wear in friction pairs of hydraulic machines. Vestn. Mashinostroeniya 2004, 9, 42-47. 
4. Yeliseev, Y.S.; Krymov, V.V.; Nezhurin, I.P.; Novikov, V.S.; Ryzhov, N.M. Production of Gear Wheels of Gas Turbine Engines; Higher school: Moscow, Russia, 2001; p. 495.

5. Kalashnikov, A.S.; Morgunov, Y.A.; Kalashnikov, P.A. Modern Methods of Processing Gears; Publishing house Spectr: Moscow, Russia, 2012; p. 238.

6. Samotugin, S.S. Plasma micro -and nanostructuring of the surface of tool steels. Reinf. Technol. Coat. 2013, 29-37.

7. Korotkov, V.A. Plasma Hardening of the Surface; STI (Branch) of UFU: Nizhny Tagil, Russia, 2012; p. 64.

8. Stavrev, D.S.; Kaputkina, L.M.; Kirov, S.K.; Shamonin, Y.V.; Prokoshkina, V.G. Influence of plasma-arc processing on structural transformations and surface hardening of carbon and alloy steels. MiTOM 1996, 16-19.

9. Stepanova, T.Y. Technologies of Surface Hardening of Machine Parts: Tutorial; Ivanovo State Chemical-Technological University: Ivanovo, Russia, 2009; p. 64.

10. Zhurerova, L.G.; Rakhadilov, B.K.; Popova, N.A.; Kylyshkanov, M.K.; Buranich, V.V.; Pogrebnjak, A.D. Effect of the PEN/C surface layer modification on the microstructure, mechanical and tribological properties of the 30CrMnSiA mild-carbon steel. J. Mater. Res. Technol. 2020, 9, 291-300. [CrossRef]

11. Suminov, I.V.; Belkin, P.N.; Epelfeld, A.V.; Lyudin, V.; Krit, B.; Borisov, A. Plasma-Electrolytic Modification of the Surface of Metals and Alloys; Suminov, I.V., Ed.; Technosphere: Moscow, Russia, 2011; p. 464.

12. Devices and Methods of Physical Metallurgy; Weinberg, F. (Ed.) Mir: Moscow, Russia, 1973; Volume 1, p. 427.

13. Gorelik, S.S.; Skakov, Y.A.; Rastorguev, L.N. X-ray and Electron-Optical Analysis; MISIS: Moscow, Russia, $2002 ;$ p. 360.

14. Grigorevich, V.K. Hardness and Microhardness of Metal; Nauka: Moscow, Russia, 1976; p. 230.

15. Zarchi, M.K.; Shariat, M.H.; Dehghan, S.A.; Solhjoo, S. Characterization of nitrocarburized surface layer on AISI 1020 steel by electrolytic plasma processing in an urea electrolyte. J. Mater. Res. Technol. 2013, 2, 213-220. [CrossRef]

16. Senatore, A.; Risitano, G.; Scappaticci, L.; D'Andrea, D. Investigation of the Tribological Properties of Different Textured Lead Bronze Coatings under Severe Load Conditions. Lubricants 2021, 9, 34. [CrossRef]

17. Duradji, V.N. Thermochemical treatment of metals with heating in electrolytic plasma. Technol. Surf. Treat. 2010, 6, 59-61.

18. Rakhadilov, B.K.; Buranich, V.V.; Satbayeva, Z.A.; Sagdoldina, Z.B.; Kozhanova, R.S.; Pogrebnjak, A.D. The cathodic electrolytic plasma hardening of the 20Cr2Ni4A chromium-nickel steel. J. Mater. Res. Technol. 2020, 9, 6969-6976. [CrossRef]

19. Rakhadilov, B.K.; Satbayeva, Z.; Baizhan, D. Effect of electrolytic-plasma surface strengthening on the structure and properties of steel $40 \mathrm{kHN}$. In Proceedings of the METAL 2019-28th International Conference on Metallurgy and Materials, Brno, Czech Republic, 22-24 May 2019; pp. 950-955.

20. Qiu, X.; Wei, X.; Xu, X.; Xu, W.; Zhu, M. Dependence of fretting wear resistance on microstructural features of alloyed steels. Tribol. Int. 2019, 137, 39-45. [CrossRef]

21. Kozlov, E.; Popova, N.; Zhurerova, L.; Nikonenko, E.; Kalashnikov, M.; Skakov, M. Structural and Phase Transformations in 0.3C-1Cr-1Mn-1Si-Fe Steel after Electrolytic Plasma Treatment. In AIP Conference Proceedings; AIP Publishing LLC: Melville, NY, USA, 2016; Volume 1783, p. 20112. 